https://helda.helsinki.fi

\title{
Partial decoupling between exotic fish and habitat constraints remains evident in late invasion stages
}

\section{Milardi, Marco}

2019-12

Milardi , M , Gavioli , A , Castaldelli , G \& Soininen , J 2019 , ' Partial decoupling between

exotic fish and habitat constraints remains evident in late invasion stages ', Aquatic

Sciences , vol. 82 , no. 1, 14 . https://doi.org/10.1007/s00027-019-0688-2

http://hdl.handle.net/10138/326460

https://doi.org/10.1007/s00027-019-0688-2

unspecified

acceptedVersion

Downloaded from Helda, University of Helsinki institutional repository.

This is an electronic reprint of the original article.

This reprint may differ from the original in pagination and typographic detail.

Please cite the original version. 


\section{Partial decoupling between exotic fish and habitat}

\section{2 constraints remains evident in late invasion stages}

4 Marco Milardi ${ }^{1}$, Anna Gavioli ${ }^{1, *}$, Giuseppe Castaldelli ${ }^{1}$, Janne Soininen $^{2}$

51 - University of Ferrara, Department of Life Sciences and Biotechnology, via Luigi Borsari 46, 6 44121, Ferrara, Italy.

72 - University of Helsinki, Department of Geosciences and Geography, PO Box 64, FI-00014, 8 Helsinki, Finland.

$9 \quad *$ Corresponding author: gvlnna@unife.it, +39 3472737393

\section{Acknowledgements}

12 We thank LL.D. V.E. Manduca and Dr. M. Rizzoli of the Fisheries Bureau of the Emilia-

13 Romagna Region for providing the Fish Inventories data in the context of a long-term research

14 collaboration. The Oglio River Water Authority (Consorzio dell'Oglio, in Italian) is also

15 acknowledged for providing fish and water quality data for the Oglio River. We also thank Dr R.

16 Spaggiari and Dr S. Franceschini of the Emilia-Romagna Region Environmental Protection

17 Agency (ARPA-EMR), the Piemonte Region Environmental Protection Agency (ARPA-

18 Piemonte) and the Veneto Region Environmental Protection Agency (ARPAV) for providing the 19 water quality database.

20 No specific funding was received for this work. 


\section{Abstract}

22 We investigated the relationships between exotic freshwater fish invasions, environmental

23 factors and ecofunctional diversity in streams. We used data from 335 stream sites belonging

24 to 105 watersheds and 3 basins in Italy to test whether the exotic species invasion was

25 dominated by species with generalist traits and whether the environment-ecofunctional trait

26 relationships of exotic and native species would differ from each other. We also tested the

27 hypothesis that ecofunctional uniqueness patterns between exotic and native species would

28 be substantially different. We found that generalist traits were widespread in nearly all areas

29 where exotic species occurred, but not all generalist traits were equally abundant in exotic

30 communities. Only temperature tolerants, low oxygen tolerants and eurytopic traits were

31 typically more dominant in exotic communities than native ones, suggesting that not all

32 generalist traits are equally important in the invasion process and that more complex

33 mechanisms of trait selection could take place. Environment-ecofunctional trait relationships

34 of exotic and native species partly differed both in direction and magnitude, suggesting that

35 invasion dynamics could partly decouple environment and biotic communities, but also that

36 this decoupling might decrease at later invasion stages. Finally, site and trait ecofunctional

37 uniqueness differed between exotic and native species and exotic species ecofunctional

38 diversity hotspots were located in human-disturbed areas, suggesting that human disturbance

39 might play a strong role in invasion patterns. We advocate for a wider use of ecofunctional

40 approaches in conservation studies in the future, as they could be a key to understand

41 complex ecological processes such as exotic invasions.

42 Keywords: biodiversity conservation, alien species, species diversity, functional diversity,

43 ecofunctional uniqueness, native species 
The study of geographical distribution of species and spatial variation of biodiversity on Earth

46 has a long history. Recently, hundreds of studies have underlined the importance of biodiversity

47 for ecosystem functioning and resilience to different pressures (e.g. Hooper et al. 2005), as well as

48 its general worldwide decline (Wiens 2016). Much effort has been devoted to investigate the

49 dispersal and evolutionary processes driving taxonomical biodiversity in the past (see e.g. Herrera

50 1995). However, the need for a shift from taxonomical to trait-based approaches in biodiversity

51 research has been acknowledged for over two decades, because of the close linkage between

52 environment and ecological traits, as well as their fast response to environmental changes (see

53 e.g.Poff et al. 2006; Violle et al. 2014). As a consequence, recent works shifted their attention

54 towards functional diversity, exploring its spatial patterns and dynamics.

55 Functional diversity quantifies the distinctive combination of morphological, biochemical,

56 physiological, structural, phenological or behavioral traits that characterizes living communities

57 and has been advocated to measure ecosystem functioning more reliably than taxonomical

58 diversity (Cadotte et al. 2011). Ecofunctional diversity, a subset of functional diversity, identifies

59 the combination of ecological traits in communities, selected by environmental conditions and

60 habitat availability (Poff and Ward 1990). Habitat diversity, geography, land use, soil or water

61 chemistry might all play a role in determining which ecofunctional traits occur in a community

62 (Comte et al. 2016). In this perspective, the habitat selects which traits prevail in a given

63 environment, ultimately linking habitat diversity with species ecofunctional diversity. This linkage

64 has been explored to infer ecological quality from ecofunctional diversity of biotic communities

65 (Milardi and Castaldelli 2018; Mouillot et al. 2013; Pont et al. 2006; Schmutz et al. 2007), but

66 exotic species invasions have been recognized as a potential confounding factor for this linkage. 
67 Exotic species introduction is a global phenomenon, and one of the main causes of biodiversity

68 loss (Leprieur et al. 2008; Sala et al. 2000) and community homogenization in space and time (e.g.

69 Rahel, 2000). Lot of attention has been devoted to investigate the consequences of exotic invasions

70 on taxonomical diversity at different geographical scales (Sax and Gaines 2003). A common

71 notion in invasion biology suggests that successful invaders in environmentally degraded areas

72 could be favored by their tolerance to a broad range of environmental conditions and their

73 generalist adaptations (Lurgi et al. 2014; Marvier et al. 2004; Milardi et al. 2018b). If most invaders

74 are generalists, invasion dynamics would override environmental drivers behind species and trait

75 distributions and cause a peculiar ecofunctional diversity distribution for exotic communities,

76 compared to that of native ones which had a longer environment-selection time and thus clear

77 environment-trait relationships. However, such difference between exotic and native communities

78 could decrease with time, as exotic species become more and more selected by environmental

79 constraints when time after invasion events passes.

80 The overall ecofunctional structure and distribution of fish has been poorly studied, so far,

81 and similarly little research exists on the impact of exotic invasions on the ecofunctional

82 structure of Mediterranean freshwater fish (Colin et al. 2018; Villéger et al. 2013). As in many

83 other geographical areas, exotic invasions are one of the main factors causing biodiversity loss,

84 but this is particularly true in the Mediterranean region and its freshwater ecosystems (Crivelli

85 1995; Cuttelod et al. 2009; Médail and Quézel 1999). Only recently, an ecofunctional

86 characterization of native and exotic fish species has been defined for some areas (Milardi and

87 Castaldelli 2018), enabling further research on the linkages between biological invasions,

88 ecofunctional diversity and the environment. 
In this study, we focused on the northern Italian peninsula, previously highlighted as a good

90 area to investigate the outcomes of freshwater fish invasions (Castaldelli et al. 2013; Gavioli et

91 al. 2018; Gavioli et al. 2019; Lanzoni et al. 2018; Milardi et al. 2018a). We used a spatially-

92 comprehensive dataset, including several river basins, to explore the spatial distribution of

93 riverine freshwater fish ecofunctional traits and investigate the relationships between

94 environmental factors and ecofunctional diversity of native and exotic species. We tested the

95 hypothesis $\left(\mathrm{H}_{1}\right)$ that the invasion process would be largely led by less-specialized species, able to

96 adapt to a wide range of environmental conditions (i.e. generalist species). Under this hypothesis,

97 we expected that generalist ecofunctional traits would be widespread and dominant in exotic

98 species communities of invaded areas, as generalist species are usually leading the invasion

99 process (e.g. Evangelista et al. 2008). However, we expected this dominance to decrease at late-

100 invasion stages. We also tested the hypothesis $\left(\mathrm{H}_{2}\right)$ that the environment-ecofunctional traits

101 relationships of exotic and native species would differ. In particular, we expected that the

102 relationships would be overall weaker for exotic species, as native species traits have been

103 selected from the regional species pool by environmental factors over a longer time than the

104 residence time of exotic species. We ultimately investigated the hypothesis $\left(\mathrm{H}_{3}\right)$ that

105 ecofunctional traits of exotic and native species would have different spatial patterns (i.e.

106 between upland and lowland streams), because lowland areas were highlighted as an invasion

107 hotspot (Lanzoni et al.2018; Milardi et al. 2018a). Finally, our results would help understanding

108 the factors shaping the ecofunctional diversity of fish communities under exotic invasions, one of

109 the major threats to native fish conservation worldwide.

110

\section{Materials \& Methods}




\section{Study area}

113 We focused our investigation on northern Italy (Fig. 1), an area hosting more than 17 million

114 inhabitants and impacted by agricultural activities and livestock farming. The study region has a

115 Mediterranean continental climate, with an annual average precipitation of $1036 \mathrm{~mm}$ and a mean

116 temperature of $12^{\circ} \mathrm{C}$. Within this area lies the largest river basin in Italy, the Po River basin $(71,000$

$117 \mathrm{~km}^{2}$ ), of which we included the Po River itself (in all its course), the Oglio River (one of the most

118 important left tributaries of the Po River) and the right tributaries in the Emilia-Romagna region.

119 We also included two additional groups of rivers outside of this basin: the Brenta River (north120 east of the Po River basin) and watercourses of the Emilia-Romagna (south of the Po River basin).

121 Overall, a total of 335 sampling sites (i.e. 335 stretches of 105 watercourses) were included in this 122 study, covering heterogeneous habitats within river ecosystem (e.g. riffles, pools), and different 123 altitudinal zones and environmental conditions (Fig. 1).

124 In the uplands, organic material originating from villages, small towns and livestock farms is 125 the main source of river pollution. Conversely, a high degree of urbanization and intensive 126 agriculture characterize the lowland rivers, where high nutrient loads have led to eutrophication 127 (Castaldelli et al. 2013). To support agricultural irrigation, a complex network of drainage canals 128 has been established in the lowlands; this system is completely human regulated with hydrological 129 management directed to both irrigation supply and drainage (Castaldelli et al. 2013; Milardi et al. 130 2017).

\section{Data collection}

132 Fish data were collected within monitoring programs of the Emilia-Romagna region (Regione 133 Emilia Romagna 2008), the Padova Province (Provincia di Padova 2010), the Po River (Autorita' 
134 di bacino del Po 2008) and the Oglio River (Consorzio dell'Oglio 2016). The monitoring programs

135 were carried out separately, in different years, over a relatively long-term period (1999-2010).

136 Fish sampling was performed by electrofishing, adapting the standard national monitoring

137 guidelines to the particular conditions of each watercourse, and using direct current at 400-600 V

138 and 4-5 A (Backiel and Welcomme 1980; Reynolds 1996). River stretches were sampled once,

139 during daylight, in an upstream zigzag direction, ensuring that the range of present macrohabitats

140 of each site was fully surveyed (Hankin and Reeves 1988). Electrofishing is considered the best

141 quantitative method for fish sampling in shallow waters, up to a maximum of $1 \mathrm{~m}$ (Zalewski and

142 Cowx 1990) but its efficacy may be low in deeper waters, with big and mobile specimens, or with

143 high conductivity. Such special conditions occurred in almost all the lower stretches of rivers and

144 in the canals of the lowlands. For this reason, at these sites, electrofishing was immediately

145 followed up with a standard set of trammel nets (with variable mesh size from 90 to $5 \mathrm{~mm}$ ), with

146 the support of professional fishermen (Backiel and Welcomme 1980). In order to allow

147 comparisons between sites (i.e. river stretches), the sampling effort at each sampling site was

148 standardized according to the national fish monitoring guidelines (APAT 2007).

149 Fish species were classified according to Kottelat and Freyhof (2007), taking into account

150 recent taxonomic determinations and common names as listed in FishBase (Froese and Pauly

151 2017). Each species was categorized as native or exotic: a species was considered as native when

152 naturally present in Italian watercourses and as exotic when human-introduced (IUCN Comitato

153 Italiano 2019; Milardi et al. 2018a), irrespective of the time elapsed since the introduction (see

154 Supplementary Table 1 for further details on introduction dates). Hybrid specimens or uncertain 155 species were excluded from this study in order to avoid taxonomic asymmetries. 
157 ranging from 1 (lower abundance, 1-2 individuals per site) to 5 (higher abundance, more than 50

158 individuals per site). However, numerical abundance classes tend to overestimate the ecological

159 significance of small-bodied species and underestimate that of large-bodied ones. A weight was

160 thus assigned to each species based on their average size published in the literature $(1=$ small body

161 up to $\sim 150 \mathrm{~g} ; 2=$ medium body $\sim 150-400 \mathrm{~g} ; 3=$ large body over $\sim 400 \mathrm{~g}$ ) and multiplied by Moyle

162 abundance classes, in order to obtain a more ecologically-balanced representation of the

163 community, closer to relative biomasses (i.e. body-mass-corrected abundances, hereafter referred

164 to simply as abundances, Milardi and Castaldelli 2018).

165 Water physicochemical sampling was performed with standard methods in temporal and

166 spatial proximity with the fish sampling, by different Regional Environmental Protection Agencies

167 (ARPAs, in Italian) for the Po, the Brenta and the rivers in the Emilia-Romagna region. The Oglio

168 River Water Authority carried out the water sampling in the Oglio River. Eight physicochemical

169 variables were monitored: water temperature $\left(T ;{ }^{\circ} \mathrm{C}\right)$, electrical conductivity $\left(E C ; \mu \mathrm{S} \mathrm{cm}^{-1}\right)$,

170 chemical oxygen demand $\left.\left(C O D ; \mathrm{O}_{2} \mathrm{mg} \mathrm{l}^{-1}\right)\right)$, biological oxygen demand $\left(B O D_{5} ; \mathrm{O}_{2} \mathrm{mg} \mathrm{l}^{-1}\right)$, total

171 suspended solids $\left(T S S ; \mathrm{mg} \mathrm{l}^{-1}\right)$, total phosphorus $\left(P ; \mathrm{mg} \mathrm{l}^{-1}\right)$, ammonia $\left(\mathrm{NH}_{4}^{+} ; \mathrm{mg} \mathrm{l}^{-1}\right)$ and nitrate

172 nitrogen $\left(\mathrm{NO}_{3}^{-} ; \mathrm{mg} \mathrm{l}^{-1}\right)$. The geographical position (longitude - Long, latitude - Lat) and the

173 altitude (Alt) were also considered.

$174 \quad$ Fish ecofunctional traits

175 In order to investigate the ecofunctional composition of fish communities, five different 176 ecological functions were taken into account: feeding, reproduction, migration, tolerance and 177 habitat use. These functions were included because of their ecological significance and close 178 relationship with the environment (Noble et al., 2007; Milardi and Castaldelli, 2018). Within these 
179 ecological functions, all fish species were classified in guilds, each representing an ecofunctional

180 trait and therefore referred as such hereafter (Table 1, see alsoNoble et al. (2007)).

181 Ecological functions, guilds and classification for most species in this study were taken from

182 Milardi and Castaldelli (2018), where all available information was used to identify appropriate

183 guilds for each species. Guilds were mutually exclusive (i.e. each species could be assigned to

184 only one guild within each ecological function) and species were classified according to their 185 prevalent adult characteristics (see also Table 1 in Milardi and Castaldelli 2018 for a more detailed 186 explanation), thus partly discounting ontogenetic shifts (e.g. in diet or habitat) and ecological 187 plasticity. The same methodology was applied to classify euryhaline species that were not included 188 in the previous work (see also Supplementary Table 1).

189 Spatial distribution of exotic species generalist traits

190 We focused our analysis on generalist ecofunctional traits, with the aim to verify their spatial 191 and community dominance within the exotic communities, therefore selecting all areas with exotic 192 species presence. Additionally the patterns observed for exotic communities were compared with 193 those found in native communities over the same areas, to investigate any differences in dominance 194 of generalist traits.

195 Inside each ecological functions, the ecological guilds indicative of no preference for, or no 196 adaptation to, specific environmental conditions (i.e. generalist traits) were selected (ecological 197 function - ecological guild): Feeding - Generalists (feeding on any source), Reproduction 198 Polyphils (spawning on any substrate), Tolerance - Low oxygen tolerants and High temperature 199 tolerants (not selective for oxygen or temperature), Habitat use - Eurytopics (adapted to a wide 200 range of current velocities) and Wide range of turbidity conditions (idem for turbidity). 
To assess the spatial distribution of generalist ecofunctional traits, the number of sites in which

202 generalist traits were detected was expressed as a share (percentage) of the total sites with exotic

203 species presence (Table 2). To assess the community dominance of generalist ecofunctional traits,

204 the share (percentage) of these traits in the communities was calculated using the abundances of

205 all species (exotic and native) possessing each generalist trait (Table 2). Both distribution and

206 dominance were also calculated separately for native and exotic communities, at each site (Table 207 2).

208 The community dominance of generalist traits of exotic and native species communities was 209 also investigated in the area where exotic and native species distributions overlapped, testing the 210 null hypothesis that exotic and native communities would not differ in generalist trait dominance.

211 Differences in generalist trait dominance were tested using the paired t-test (paired-t, a parametric 212 paired test) and the Wilcoxon signed-rank test (Wilcoxon, a non-parametric paired test), which 213 investigate differences in the mean and median, respectively. Testing was performed using the 214 PAST 3.06 software (Hammer et al. 2001).

215 The ArcGIS software (ESRI 2011) was used to map the spatial distribution of ecofunctional 216 traits in exotic communities, and to investigate the spatial autocorrelation of each generalist trait, 217 using the Spatial Autocorrelation (Global Moran's I) tool. The null hypothesis of the Global 218 Moran's I analysis is that the attribute being analyzed is randomly distributed among the features 219 in the study area. Being an inferential statistic, positive (and significant) values of the Global 220 Moran's I indicate spatial clustering of a generalist trait.

221 Exotic and native species environment-ecofunctional traits relationships

222 Land cover data were obtained from the CORINE database (2012, 223 https://www.eea.europa.eu/data-and-maps/data/copernicus-land-monitoring-service-corine). In 
224 the lowlands, where estimation of watershed areas is more difficult due to low slopes and human-

225 regulated flow, the land cover of the whole river basin or of the administrative province was used.

226 CORINE land cover classes were merged in five categories based on the main land use in order to

227 better describe the study area: urban use (Urban), agricultural use (Agri), forest (Forest), other

228 natural area (OtherNat), freshwater (Fresh) and brackish water (Brack). Land cover was expressed

229 as the share of each of these categories in the watershed of each site.

230 Relationships between geographical variables, land use features, water physico-chemical

231 variables and fish ecofunctional traits were explored using the distance-based Redundancy

232 Analysis (db-RDA, Legendre and Anderson 1999). This analysis is normally used to analyze

233 species-by-site data, but here it was used to analyze trait-by-site data (i.e. the total body-size-

234 corrected abundance of all species with a certain ecological trait at each site). One of the

235 advantages of db-RDA is that it can be used with any non-Euclidean distance measures (Legendre

236 and Anderson 1999). Therefore, taking into account the work of de Bello et al. (2013), Gower

237 distance measures were used because of their better suitability in detecting changes in

238 ecofunctional diversity along environmental gradients. Linear dependencies between variables

239 were assessed through the Variance Inflation Factors (VIF) and variables showing high collinearity

240 (VIF > 10) were removed from the analysis (Borcard et al. 2011). Explained variance in db-RDA

241 was reported through adjusted $\mathrm{r}^{2}$ values (correct constrained variance).

242 Matrices of traits-by-site data were Hellinger transformed (Legendre and De Cáceres 2013;

243 Legendre and Gallagher 2001) to standardize variations among both species and community size.

244 Environmental variables expressed as percentages were arcsine transformed, while all the other

245 ones were log-transformed. 
247 analysis used the capscale function within the 'vegan' R package (Oksanen et al. 2017) on all

248 species, and also separately for native and exotic species.

249 Ecofunctional uniqueness patterns of native and exotic species

250 Stream order for each site was calculated using a Digital Elevation Model (DEM)

251 (http://www.sinanet.isprambiente.it/it/sia-ispra/download-mais/dem20/view), resampled into 10

252 m pixel size to harmonize it. Flow direction and accumulation, as well as the watershed of each

253 sampling site, were calculated based on the DEM layer. For the entire river network generated by

254 flow accumulation, stream order was derived with the Strahler method (Strahler 1957). This

255 procedure was reliable for upland streams, but it was less so in the lowland, possibly due to the

256 fact that flow direction and magnitude in the lowlands are not always natural because of human

257 intervention. The stream order was thus manually checked and revised when necessary in lowland

258 rivers and streams. Rivers were grouped into four classes based on stream order: class 1 (Strahler

259 stream order 1 and 2), class 2 (stream order3 and 4), class 3 (stream order5 and 6) and class 4

260 (stream order $>6$ ). As drainage and irrigation canals could not be assigned into any natural class,

261 a separate class called "Canals" was created. Canals are man-made environments, usually

262 characterized by low habitat heterogeneity and controlled hydrology, located in the lowlands

263 southwest of the Po River, near its delta.

264 The ecofunctional uniqueness of communities across sites was investigated with the Local

265 Contribution to Beta Diversity (LCBD) and Species Contribution to Beta Diversity (SCBD)

266 approaches, developed by Legendre and De Cáceres (2013), accounting for stream order. These

267 analyses were originally developed to calculate the total beta diversity from the total variance of a

268 site, partitioning the total variance into local contributions to beta diversity (i.e. LCBD), and 
269 species contributions to beta diversity (i.e. SCBD) across the area, respectively. However, for the

270 first time, the same approach was applied here to the ecofunctional diversity of communities: high

271 values of LCBD indicate a unique econfunctional composition of the local community (arising

272 from a combination of low ecofunctional diversity, low species richness and a rare distribution in

273 the sites) and low values of SCBD highlight those ecofunctional traits that are the most unique in

274 the data (arising from the uniqueness of traits and their rare distribution in the dataset).

275 Uniqueness analyses were performed in R software version 3.4.3 (R Core Team 2017)

276 through the 'vegan' R package (Oksanen et al. 2017) and the 'adespatial' R package (Dray et al.

277 2016) on all species, and also separately for native and exotic species.

278

279 Results

280 A total of 59 fish species were detected in the study area; of these 37 were native and 22

281 were exotic species. Each of these species was assigned to guilds within ecological functions, as

282 defined in Table 1 (see also Supplementary Table 1).

283 Spatial distribution of exotic species`generalist traits

284 Exotic species were rather widespread in the area (209 out of 335 sites, $62.4 \%$ of the total)

285 and occurred mostly in the lowlands. Exotic species occasionally reached rather high abundances

286 (abundance $\geq 40$ in 12 sites, Fig. 2 a, and constituting $100 \%$ of the fish community in 9 sites).

287 Overall, generalist traits were overall widely distributed in the area occupied by exotics, but not 288 all traits were equally dominant in the exotic communities. The three most widespread generalist 289 traits were low oxygen tolerance, high temperature tolerance and eurytopic adaptation to current 290 velocity $(98.1 \%, 97.6 \%$ and $94.7 \%$ of the sites, respectively, Fig. 2 d, e and f, Table 2$)$. The least 
291 widespread traits were polyphily and adaptation to a wide range of turbidity conditions $(31.1 \%$ 292 and $79.4 \%$ of the sites, respectively, Fig. 2c and g).

293 Generalist feeder traits were relatively widespread (80.9\% of the sites, Fig. 2b), but were a

294 minor component of the community (18.6\% of the total abundance, Table 2$)$, on average.

295 Polyphil traits dominance was also very low, totaling $4.9 \%$ of the overall abundance, on average.

296 Generalist traits were relatively slightly less widespread within the native species communities

297 present in the same area, with the exception of adaptations to a wide range of turbidity conditions

298 (94.3\% of the sites, Table 2). However, rather surprisingly, some generalist traits were in general

299 more dominant in native communities than exotic ones (H1). Generalists feeders, polyphils and

300 species adapted to a wide range of turbidity were all more dominant in native communities than

301 exotic ones, while high temperature tolerants, low oxygen tolerants and eurytopics and were less 302 dominant (Table 2).

303 Differences in dominance of generalist traits between native and exotic communities were 304 statistically significant for adaptations to a wide range of turbidity, high temperature tolerance 305 and low oxygen tolerance (paired-t $\mathrm{P}<0.01$, Wilcoxon $\mathrm{P}<0.01$, for all these traits), as well as 306 for polyphily and eurytopic adaptation to current velocity (paired-t $\mathrm{P}<0.05$, Wilcoxon $\mathrm{P}<0.05$ ),

307 but not for generalist feeders (paired-t $\mathrm{P}=0.19$, Wilcoxon $\mathrm{P}=0.85$ ). All generalist traits showed 308 a significant spatial clustering (Global Moran's I > 0; P-values $<0.001$, for all traits), indicating 309 spatial autocorrelation.

\section{Exotic and native species environment-ecofunctional traits relationships}

311 Environmental variables did not show collinearity $(\mathrm{VIF}<10)$ and they were thus all included 312 in the db-RDA analysis. The total amount of ecofunctional trait variance in the communities 313 explained by db-RDA was $41.90 \%$ (Fig. 3a). The first axis explained $30.13 \%$ of the variance and 
314 the second axis explained $4.36 \%$ of the variance (Fig. 3a). Most ecofunctional traits were related

315 to environmental features (e.g. rheophile (Rhe), low oxygen intolerant (OxInt) and clear water

$316(\mathrm{CW})$ adapted species at higher elevations and vice versa), but some traits (e.g. herbivore $(\mathrm{H})$ or

317 parasite $(\mathrm{Pa})$ feeding) did not clearly relate with environmental variables (Fig. 3a). Overall, the

318 environmental factors most strongly related with ecofunctional traits were altitude, temperature

319 and stream order class, which are all closely linked to each other and influenced both native and

320 exotic species. The db-RDA analysis conducted exclusively on native species $(50.12 \%$ of

321 variance explained) showed a clear distribution of ecofunctional traits (Fig. 3b, the first axis

322 explained the $29.43 \%$ of the variance and the second axis explained the $11.63 \%$ of the variance),

323 with clear distinctions related to environmental features, similar to those found in the general

324 analysis. Exotic species had an overall lower linkage with environmental variables (35.46\% of

325 variance explained) (Fig. 3c, the first axis explained the $15.23 \%$ of the variance and the second

326 axis explained the $7.77 \%$ of the variance). In general, these three analyses revealed similarities

327 along the first ordination axis in terms of the key environmental variables (altitude, forests,

328 temperature), whereas results differed clearly more for the second axis in terms of which

329 environmental variables drove trait composition.

330 Ecofunctional uniqueness patterns of native and exotic species

331 According to the LCBD analysis, the degree of uniqueness of the communities'

332 econfunctional composition per each stream order class showed a clear decreasing pattern with

333 increasing stream order class (Fig. 4a). Communities in lower stream orders (in the uplands) had

334 high values of ecofunctional uniqueness, but communities in canals also showed a surprisingly

335 high degree of uniqueness compared with other lowland sites (Fig. 4a). According to the SCBD

336 analysis, high ecofunctional uniqueness was associated with clear water adaptation, intermediate 
337 migration and low oxygen tolerance traits (Fig. 4b). Herbivorous, planktivorous and parasitic

338 feeding traits were associated with low uniqueness (Fig. 4b). The econfunctional uniqueness of

339 native communities (LCBD analysis) followed a similar pattern than that underlined in overall

340 communities (Fig. 4c), but a comparison with exotic species (Fig. 4e) revealed that the latter

341 contributed the least to uniqueness in higher stream orders and canals. Agreeing with our

342 hypothesis $\mathrm{H}_{3}$, uniqueness patterns differed between native and exotic species. Among native

343 species, litophilic, low oxygen tolerant and clear water traits contributed the most to uniqueness

344 according to the SCBD analysis (Fig. 4d), while planktivory, pelagic spawning and parasitism

345 contributed the least. Among exotic species, piscivory, phytophily and benthivory were the traits

346 that contributed the most to uniqueness according to the SCBD analysis (Fig. 4f), while low

347 oxygen tolerance, herbivory and pelagic spawning contributed the least.

349 Discussion

350 Our results partly agreed with our initial hypothesis $\left(\mathrm{H}_{1}\right)$ that generalist traits were

351 widespread in nearly all areas with exotic species presence, but not all generalist traits were

352 equally abundant in the exotic communities. Moreover, only temperature tolerants, low oxygen

353 tolerants and eurytopic traits were typically more dominant in exotic communities than native

354 ones, suggesting that not all generalist traits are equally determinant in the invasion process and

355 that more complex mechanisms of trait selection could be in place. Our analyses underlined

356 strong linkages between the environment and ecofunctional traits for both native and exotic

357 species but, as we hypothesized $\left(\mathrm{H}_{2}\right)$, environmental variables explained overall a lower

358 proportion of exotic species traits than of native traits. This suggests that the linkage between

359 exotic traits and environmental factors was less evident, i.e. that the environment explained less 
360 the trait composition of exotic species than that of native species, even at the late-invasion stage.

361 This suggests that invasion dynamics could partly override habitat selectivity resulting in a

362 partial uncoupling of environment and biotic communities, and that these effects last long.

363 Finally, we found some differences in the ecofunctional uniqueness patterns of native and exotic

364 species and their respective ecofunctional traits, being in line with our third hypothesis $\left(\mathrm{H}_{3}\right)$.

365 Exotic species ecofunctional diversity hotspots were common in human-disturbed areas,

366 suggesting that human disturbance might play a strong role in invasion patterns.

367 Spatial distribution of exotic species`generalist traits

368 It was clear from our results that exotic species presence was relatively low in upland areas,

369 likely halted by natural gradients (e.g. temperature and habitat factors) or perhaps by physical

370 dispersal barriers (Dynesius and Nilsson 1994; Tockner and Stanford 2002). On the contrary,

371 exotic species were widespread in the lowlands, therefore still exerting a significant propagule

372 pressure in the less-invaded areas in the foothills (Lockwood et al. 2005; Simberloff 2009).

373 Generalist traits were widespread in exotic communities of the lowlands, but not all traits were

374 equally represented. Furthermore, generalist trait distribution was not the result of a random

375 process, but different selection processes operate on different ecological functions $\left(\mathrm{H}_{1}\right)$. Some

376 traits related to broad tolerance and flexible habitat use (temperature tolerance, low oxygen

377 tolerance and adaptation to a wide range of water current conditions) were dominant among

378 exotic communities (and more so than in native communities). However, reproductive polyphily

379 and adaptation to a wide range of turbidity were more dominant in native communities over the

380 same area, indicating that perhaps not all generalist traits are equally relevant to determine

381 invasion success. The timeline of invasion processes could partly explain this complex result:

382 early invasion phases could be spearheaded by true generalists, but on the long run more 
383 specialized species can also be introduced and spread in the area, overriding some of the overall

384 invasion patterns (Nagelkerke et al. 2018). As this area is in a late invasion stage (Milardi et al.

385 2018a), what we observe could be the result of the complex interactions between species-specific

386 introduction timing and mechanisms of dispersal and interaction with native species, as well as

387 the overall outcome of longer-term environmental selection of exotic communities. These

388 mechanisms could not be fully disentangled through our analysis, and should be further

389 investigated in future studies, also considering that the spatial scale covered could influence the

390 results (Taylor et al. 2019).

391 Exotic and native species environment-ecofunctional traits relationships

392 Our results confirmed that there are differences in how the environmental variables influence

393 the distribution of traits for native and exotic species $\left(\mathrm{H}_{2}\right)$. The fact that native species

394 ecofunctional traits are more clearly coupled with the environment confirms our initial

395 hypothesis of a longer selection time. This tighter coupling of environmental niches was found in 396 other taxa (Marks and Lechowicz 2005), but very few studies have dealt with this aspect in fish 397 communities, so far (but see e.g. Buckwalter et al. 2018). Ecological theory predicts that exotic 398 species should be equally influenced and selected by the environment, eventually, but evidently 399 this selection could take a much longer time than that elapsed in our study area (Lambrinos 400 2004). The lower influence of the environment on exotic species ecofunctional traits suggests 401 that invasion dynamics might still play a role in the observed ecofunctional distributions (Strayer 402 et al. 2006). Among invasion dynamics, the introduction of new species through fisheries 403 stocking practices and active dispersal by anglers could confound spatial distribution patterns 404 and their linkage with the environment, for both exotic and native species (Hesthagen and 405 Sandlund 2007; Vörösmarty et al. 2010). Moreover, invasion processes are not driven by abiotic 
factors only, and the invasion of one species could facilitate the invasions of other species

407 (Simberloff and Von Holle 1999), a mechanism previously suggested to be at play in this area

408 (Lanzoni et al. 2018; Milardi et al. 2018a). Our results confirmed that exotic species are less

409 affected by habitat filtering than native species, even at late-invasion stages.

410

411

412

413 rivers in the lowlands (Aschonitis et al. 2018; Bouska 2018). This could also be linked to a lower

414 taxonomical diversity in these areas (Gavioli et al. 2019) as species number is known to affect

415 uniqueness measures (Legendre 2014). Conversely, ecofunctional diversity was relatively higher

416 in higher stream orders and in the lowlands, with the exception of canals, which had a lower

417 ecofunctional diversity than natural rivers in the same areas. Canals should have low-

418 heterogeneity habitats, due to their artificial nature, which can partly explain this result.

419 However, our analysis highlighted that native species low ecofunctional diversity played a strong

420 role in shaping this uniqueness pattern. Previous studies have underlined how freshwater fish

421 invasions have caused a severe decrease of native taxonomical diversity at the local level,

422 especially in canals (Castaldelli et al. 2013; Milardi et al. 2018b) and low species richness could

423 be at the root of the low native ecofunctional diversity seen in canals. On the contrary, exotic

424 ecofunctional diversity was highest in the lowlands and particularly in canals, which could be

425 caused by a high number of ecofunctionally diverse exotic species. Canals in this area are indeed

426 hotspots of exotic species diversity (Lanzoni et al. 2018) and host the highest number of exotic

427 species in our dataset. This is somewhat counterintuitive, given the canals' simplified habitats,

428 but could be explained by the higher degree of human disturbance. In the studied canal network, 
429 human intervention continuously causes redistribution of fish species between different canals,

430 thus likely increasing the spread and colonization of exotic species (Castaldelli et al. 2013). Our

431 results suggested that exotic invasions might contribute to shaping the spatial patterns of

432 ecofunctional diversity in fish communities.

433 Clear water, rheophilic, intermediate migration, phytophylic, lithophylic and piscivorous

434 species seem to contribute the most to the overall ecofunctional uniqueness of fish communities

435 in the area, being typical traits of native species and most likely belonging to species with

436 intermediate site occupancy. However, perhaps more interesting are those ecofunctional traits

437 which are rarest in the dataset, as they highlight the presence of ecofunctionally unique and

438 relatively rare native marine species (e.g. planktivores), temporarily entering estuarine and

439 upstream freshwater areas. Rare ecofunctional traits also highlight the presence of hard-to-detect

440 exotic species (e.g. herbivores, such as grass carp, Ctenopharyngodon idella), which were found

441 only in canals during standard monitoring, but are also present elsewhere in the Po River basin

442 (Milardi et al. 2017; Milardi et al. 2015). Further investigations are needed to unravel the exact

443 contribution of species richness, ecofunctional diversity and its spatial distribution on the

444 ecofunctional uniqueness of communities, as well as the relationship between ecofunctional

445 uniqueness and trait diversity.

\section{Conclusions}

447 Our results underlined how the decoupling of the environment-ecofunctional trait

448 relationships of exotic species is still detectable in late invasions stages, and how invasions might

449 affect the ecofunctional diversity patterns of fish communities. However, other factors

450 potentially affecting functional diversity (e.g. climate change and habitat loss) should also be 
451 investigated, as they might provide useful insights on the final outcome of exotic and native

452 species interactions.

453 Our results also highlighted the importance of extending the analysis from taxonomical to

454 functional diversity, when attempting to address the complexity of species interactions in

455 invaded communities (see e.g. Colin et al. 2018; Godoy 2019; Trivellone et al. 2014). We thus

456 advocate for a wider use of ecofunctional approaches in the future to evaluate the consequences

457 of exotic species invasions (Griffiths and Harris 2010; Loiola et al. 2018; Schlaepfer et al. 2011),

458 and consequently when drafting conservation and management plans aimed at preserving native

459 biodiversity from exotic invasions.

\section{References}

APAT (2007) Protocollo di campionamento e analisi della fauna ittica dei sistemi lotici. ICRAM, Roma intervention for the recovery of native fish populations using hierarchical ranking of environmental and exotic species impact J Environ Manage 210:36-50

Autorita' di bacino del Po (2008) Monitoraggio dell'ittiofauna e redazione della Carta ittica del Fiume Po. Qualità dell'ittiofauna e del macrobenthos del fiume Po.

Backiel T, Welcomme RL (1980) Guidelines for sampling fish in inland waters

Borcard D, Gillet F, Legendre P (2011) Spatial analysis of ecological data. In: Numerical ecology with R. Springer, pp 227-292

Bouska KL (2018) Discontinuities and functional resilience of large river fish assemblages Ecosphere 9:e02351

Buckwalter JD, Frimpong EA, Angermeier PL, Barney JN (2018) Seventy years of stream-fish collections reveal invasions and native range contractions in an Appalachian (USA) watershed Divers Distrib 24:219-232

Cadotte MW, Carscadden K, Mirotchnick N (2011) Beyond species: functional diversity and the maintenance of ecological processes and services Journal of applied ecology 48:1079-1087

Castaldelli G, Pluchinotta A, Milardi M, Lanzoni M, Giari L, Rossi R, Fano EA (2013) Introduction of exotic fish species and decline of native species in the lower Po basin, north-eastern Italy Aquatic Conservation: Marine and Freshwater Ecosystems 23:405-417 doi:10.1002/aqc.2345

Colin N, Villéger S, Wilkes M, de Sostoa A, Maceda-Veiga A (2018) Functional diversity measures revealed impacts of non-native species and habitat degradation on species-poor freshwater fish assemblages Science of the Total Environment 625:861-871 
484

Comte L, Cucherousset J, Boulêtreau S, Olden JD (2016) Resource partitioning and functional diversity of worldwide freshwater fish communities Ecosphere 7:e01356

Consorzio dell'Oglio (2016) Progetto di Sperimentazione dei rilasci per il deflusso minimo vitale nel fiume Oglio sub lacuale. Relazione conclusiva 2009-2015.

Crivelli A (1995) Are fish introductions a threat to endemic freshwater fishes in the northern Mediterranean region? Biological Conservation 72:311-319

Cuttelod A, García N, Malak DA, Temple HJ, Katariya V (2009) The Mediterranean: a biodiversity hotspot under threat Wildlife in a Changing World-an analysis of the 2008 IUCN Red List of Threatened Species 89

de Bello F, Carmona CP, Mason NW, Sebastià MT, Lepš J (2013) Which trait dissimilarity for functional diversity: trait means or trait overlap? Journal of Vegetation Science 24:807-819

Dray S, Blanchet G, Borcard D, Guenard G, Jombart T, Legendre P, Wagner H (2016) Package 'adespatial': multivariate multiscale spatial analysis.

Dynesius M, Nilsson C (1994) Fragmentation and flow regulation of river systems in the northern third of the world Science 266:753-762

ESRI (2011) ArcGIS Desktop vol 10.1. Environmental Systems Research Institute, Redlands, CA

Evangelista PH, Kumar S, Stohlgren TJ, Jarnevich CS, Crall AW, Norman III JB, Barnett DT (2008) Modelling invasion for a habitat generalist and a specialist plant species Divers Distrib 14:808817

Froese R, Pauly D (2017) FishBase. Version 03/2017 World Wide Web electronic publication, R Froese and D Pauly (eds) Available at: www fishbase org Accessed April 2017

Gavioli A, Mancini M, Milardi M, Aschonitis V, Racchetti E, Viaroli P, Castaldelli G (2018) Exotic species, rather than low flow, negatively affect native fish in the Oglio River, Northern Italy River Research and Applications:1-11 doi:10.1002/rra.3324

Gavioli A, Milardi M, Castaldelli G, Soininen J (2019) Diversity patterns of native and exotic fish species suggest homogenization processes, but partly fail to highlight extinction threats Divers Distrib, in press

Godoy O (2019) Coexistence theory as a tool to understand biological invasions in species interaction networks: Implications for the study of novel ecosystems Funct Ecol

Griffiths CJ, Harris S (2010) Prevention of secondary extinctions through taxon substitution Conservation Biology 24:645-646

Hammer $\varnothing$, Harper D, Ryan P (2001) PAST: Paleontological statistics software package for education and data analysis vol 4. Palaeontologia Electronica, vol 1.

Hankin DG, Reeves GH (1988) Estimating total fish abundance and total habitat area in small streams based on visual estimation methods Canadian journal of fisheries and aquatic sciences 45:834844

Herrera CM (1995) Dispersal systems in the Mediterranean: ecological, evolutionary, and historical determinants Annual Review of Ecology and Systematics 26:705-727

Hesthagen T, Sandlund O (2007) Non-native freshwater fishes in Norway: history, consequences and perspectives J Fish Biol 71:173-183

Hooper DU et al. (2005) Effects of biodiversity on ecosystem functioning: a consensus of current knowledge Ecological monographs 75:3-35

IUCN Comitato Italiano (2019) Italian red list of species - Osteichthyes. http://www.iucn.it/classeosteichthyes.php. Accessed April 2019

Kottelat M, Freyhof J (2007) Handbook of European freshwater fishes. Publications Kottelat, Cornol Lambrinos JG (2004) How interactions between ecology and evolution influence contemporary invasion dynamics Ecology 85:2061-2070 
Lanzoni M, Milardi M, Aschonitis V, Fano EA, Castaldelli G (2018) A regional fish inventory of inland waters in Northern Italy reveals the presence of fully exotic fish communities The European Zoological Journal 85:1-7 doi:10.1080/24750263.2017.1415384

Legendre $\mathrm{P}$ (2014) Interpreting the replacement and richness difference components of beta diversity Global Ecology and Biogeography 23:1324-1334

Legendre P, Anderson MJ (1999) Distance-based redundancy analysis: testing multispecies responses in multifactorial ecological experiments Ecological monographs 69:1-24

Legendre P, De Cáceres M (2013) Beta diversity as the variance of community data: dissimilarity coefficients and partitioning Ecology letters 16:951-963

Legendre P, Gallagher ED (2001) Ecologically meaningful transformations for ordination of species data Oecologia 129:271-280

Leprieur F, Beauchard O, Blanchet S, Oberdorff T, Brosse S (2008) Fish Invasions in the World's River Systems: When Natural Processes Are Blurred by Human Activities PLOS Biology 6:e28 doi:10.1371/journal.pbio.0060028

Lockwood JL, Cassey P, Blackburn T (2005) The role of propagule pressure in explaining species invasions Trends in Ecology \& Evolution 20:223-228

Loiola PP, de Bello F, Chytrý M, Götzenberger L, Carmona CP, Pyšek P, Lososová Z (2018) Invaders among locals: Alien species decrease phylogenetic and functional diversity while increasing dissimilarity among native community members Journal of Ecology 106:2230-2241

Lurgi M, Galiana N, López BC, Joppa LN, Montoya JM (2014) Network complexity and species traits mediate the effects of biological invasions on dynamic food webs Frontiers in Ecology and Evolution 2:36

Marks CO, Lechowicz MJ (2005) Alternative designs and the evolution of functional diversity The American Naturalist 167:55-66

Marvier M, Kareiva P, Neubert MG (2004) Habitat destruction, fragmentation, and disturbance promote invasion by habitat generalists in a multispecies metapopulation Risk Analysis: An International Journal 24:869-878

Médail F, Quézel P (1999) Biodiversity hotspots in the Mediterranean Basin: setting global conservation priorities Conservation biology 13:1510-1513

Milardi M, Aschonitis V, Gavioli A, Lanzoni M, Fano EA, Castaldelli G (2018a) Run to the hills: exotic fish invasions and water quality degradation drive native fish to higher altitudes Science of The Total Environment 624:1325-1335 doi:10.1016/j.scitotenv.2017.12.237

Milardi M, Castaldelli G (2018) A novel approach to an ecofunctional fish index for Mediterranean countries Ecological Indicators 89:376-385 doi:10.1016/j.ecolind.2018.02.022

Milardi M, Chapman D, Lanzoni M, Long JM, Castaldelli G (2017) First evidence of bighead carp wild recruitment in Western Europe, and its relation to hydrology and temperature PloS one 12:e0189517 doi:10.1371/journal.pone.0189517

Milardi M, Lanzoni M, Gavioli A, Fano EA, Castaldelli G (2018b) Long-term fish monitoring underlines a rising tide of temperature tolerant, rheophilic, benthivore and generalist exotics, irrespective of hydrological conditions Journal of Limnology doi:10.4081/jlimnol.2018.1745

Milardi M, Lanzoni M, Kiljunen M, Torniainen J, Castaldelli G (2015) Natural recruitment contributes to high densities of grass carp Ctenopharyngodon idella (Valenciennes, 1844) in Western Europe Aquatic Invasions 10:439-448 doi:10.3391/ai.2015.10.4.07

Mouillot D, Graham NA, Villéger S, Mason NW, Bellwood DR (2013) A functional approach reveals community responses to disturbances Trends in ecology \& evolution 28:167-177

Moyle PB, Nichols RD (1973) Ecology of some native and introduced fishes of the Sierra Nevada foothills in central California Copeia:478-490 
Nagelkerke LA, van Onselen E, van Kessel N, Leuven RS (2018) Functional feeding traits as predictors of invasive success of alien freshwater fish species using a food-fish model PloS one 13:e0197636

Noble R, Cowx I, Goffaux D, Kestemont P (2007) Assessing the health of European rivers using functional ecological guilds of fish communities: standardising species classification and approaches to metric selection Fisheries Management and Ecology 14:381-392

Oksanen J et al. (2017) vegan: Community Ecology Package, 2.4-2.

Poff NL, Olden JD, Vieira NK, Finn DS, Simmons MP, Kondratieff BC (2006) Functional trait niches of North American lotic insects: traits-based ecological applications in light of phylogenetic relationships J N Am Benthol Soc 25:730-755

Poff NL, Ward J (1990) Physical habitat template of lotic systems: recovery in the context of historical pattern of spatiotemporal heterogeneity Environmental management 14:629

Pont D et al. (2006) Assessing river biotic condition at a continental scale: a European approach using functional metrics and fish assemblages Journal of Applied Ecology 43:70-80

Provincia di Padova (2010) Carta ittica: aggiornamento dello stato delle conoscenze sui popolamenti ittici della Provincia di Padova.

R Core Team (2017) R: A language and environment for statistical computing. Vienna, Austria; 2014.

Regione Emilia Romagna (2008) Carta ittica dell'Emilia Romagna - Zone A e B. Assessorato Attività Produttive, Sviluppo Economico e Piano Telematico., Bologna

Reynolds JB (1996) Electrofishing Fisheries techniques:221-254

Sala OE et al. (2000) Global biodiversity scenarios for the year 2100 science 287:1770-1774

Sax DF, Gaines SD (2003) Species diversity: from global decreases to local increases Trends in Ecology \& Evolution 18:561-566

Schlaepfer MA, Sax DF, Olden JD (2011) The potential conservation value of non-native species Conservation Biology 25:428-437

Schmutz S, Cowx I, Haidvogl G, Pont D (2007) Fish-based methods for assessing European running waters: a synthesis Fisheries Management and Ecology 14:369-380

Simberloff D (2009) The role of propagule pressure in biological invasions Annual Review of Ecology, Evolution, and Systematics 40:81-102

Simberloff D, Von Holle B (1999) Positive interactions of nonindigenous species: invasional meltdown? Biol Invasions 1:21-32

Strahler AN (1957) Quantitative analysis of watershed geomorphology Eos, Transactions American Geophysical Union 38:913-920

Strayer DL, Eviner VT, Jeschke JM, Pace ML (2006) Understanding the long-term effects of species invasions Trends in ecology \& evolution 21:645-651

Taylor CM, Miyazono S, Cheek CA, Edwards RJ, Patiño R (2019) The spatial scale of homogenisation and differentiation in Chihuahuan Desert fish assemblages Freshwater biology 64:222-232

Tockner K, Stanford JA (2002) Riverine flood plains: present state and future trends Environ Conserv 29:308-330

Trivellone V, Schoenenberger N, Bellosi B, Jermini M, De Bello F, Mitchell EA, Moretti M (2014) Indicators for taxonomic and functional aspects of biodiversity in the vineyard agroecosystem of Southern Switzerland Biological conservation 170:103-109

Villéger S, Grenouillet G, Brosse S (2013) Decomposing functional $\beta$-diversity reveals that low functional $\beta$-diversity is driven by low functional turnover in $E$ uropean fish assemblages Global Ecology and Biogeography 22:671-681

Violle C, Reich PB, Pacala SW, Enquist BJ, Kattge J (2014) The emergence and promise of functional biogeography Proceedings of the National Academy of Sciences 111:13690-13696

Vörösmarty CJ et al. (2010) Global threats to human water security and river biodiversity Nature 467:555 
626 Wiens JJ (2016) Climate-related local extinctions are already widespread among plant and animal 627 species PLoS Biology 14:e2001104

628 Zalewski M, Cowx I (1990) Factors affecting the efficiency of electric fishing Fishing with electricity: 629 applications in freshwater fisheries management Fishing News Books, Oxford, UK:89-111

630

631 


\section{Tables}

633

634 Table 1 - Ecological functions and guilds (and their abbreviations) considered for each species in

635 this study. Edited from Milardi and Castaldelli (2018).

\section{Ecological function Guild}

\begin{tabular}{|c|c|c|c|}
\hline \multirow[t]{7}{*}{ Feeding } & Planktivores & $\mathrm{P}$ & Plankton feeders \\
\hline & Herbivores & $\mathrm{H}$ & Vegetation feeders \\
\hline & Benthivores & B & Bottom feeders \\
\hline & Invertivores & I & Invertebrate feeders \\
\hline & Piscivores & $\mathrm{Pi}$ & Fish feeders \\
\hline & Parasite & $\mathrm{Pa}$ & Ematophages \\
\hline & Generalists & G & Unspecialized feeding \\
\hline \multirow[t]{8}{*}{ Reproduction } & Lithophils & Lp & Spawning on stones or gravel \\
\hline & Phytophils & $\mathrm{Pp}$ & Spawning on submerged vegetation \\
\hline & Phytolithophils & $\mathrm{PL}$ & Spawning on stones or vegetation \\
\hline & Psammophils & PS & Spawning on sand or mud \\
\hline & Ostracophils & 0 & Spawning in molluscs \\
\hline & Pelagophils or live breeding & LB & Pelagic spawners or live spawners \\
\hline & Polyphils & Pps & Generalist spawners \\
\hline & Sea spawning & Sea & Saltwater spawners \\
\hline \multirow[t]{3}{*}{ Migration } & Short & $S$ & Within or close to the site \\
\hline & Intermediate & M & Up and downstream or into flooded areas \\
\hline & Long & $\mathrm{L}$ & Anadromous and catadromous species \\
\hline \multirow[t]{4}{*}{ Tolerance } & Low oxygen tolerants & OxT & Tolerance/intolerance to low oxygen \\
\hline & Low oxygen intolerants & OxInt & (indicatively below 3 ppm) \\
\hline & High temperature tolerants & $\mathrm{HTT}$ & Tolerance/intolerance to high temperature \\
\hline & High temperature intolerants & HTInt & (indicatively above $20^{\circ} \mathrm{C}$ ) \\
\hline \multirow[t]{6}{*}{ Habitat use } & Rheophiles & Rhe & Preferring fast flowing water \\
\hline & Limnophiles & Lim & Preferring slow or no current \\
\hline & Eurytopics & Eur & Having no preference on current velocity \\
\hline & Clear water & $\mathrm{CW}$ & Clear water adapted \\
\hline & Turbid water & TW & Turbid water adapted \\
\hline & Wide range of conditions & WR & Adapted to a wide range of water turbidity \\
\hline
\end{tabular}


640 Table 2 - Distribution and average abundance of generalist ecofunctional traits in the area

641 where native and exotic species distribution overlapped

\begin{tabular}{|c|c|c|c|c|c|}
\hline \multirow[b]{2}{*}{$\begin{array}{l}\text { Ecological } \\
\text { Function }\end{array}$} & \multirow[b]{2}{*}{ Trait } & \multicolumn{2}{|c|}{ Exotic community } & \multicolumn{2}{|c|}{ Native community } \\
\hline & & $\begin{array}{c}\text { Distribution } \\
\text { (\% sites with trait } \\
\text { presence) }\end{array}$ & $\begin{array}{l}\text { Average } \\
\text { dominance } \\
\text { (\% of fish } \\
\text { community) }\end{array}$ & $\begin{array}{c}\text { Distribution } \\
\text { (\% sites with trait } \\
\text { presence) }\end{array}$ & $\begin{array}{c}\text { Average } \\
\text { dominance } \\
\text { (\% of fish } \\
\text { community) }\end{array}$ \\
\hline Feeding & Generalists & 80.9 & 18.6 & 67.0 & 22 \\
\hline Reproduction & Polyphils & 31.1 & 4.9 & 29.2 & 8.3 \\
\hline Tolerance & $\begin{array}{l}\text { Low oxygen } \\
\text { tolerants }\end{array}$ & 98.1 & 95.9 & 84.2 & 53.3 \\
\hline \multirow{3}{*}{ Habitat use } & $\begin{array}{l}\text { High temperature } \\
\text { tolerants }\end{array}$ & 97.6 & 94 & 84.2 & 49.4 \\
\hline & Eurytopics & 94.7 & 71 & 91.4 & 65.7 \\
\hline & $\begin{array}{l}\text { Wide range of } \\
\text { turbidity }\end{array}$ & 79.4 & 25.3 & 94.3 & 71.9 \\
\hline
\end{tabular}

642

643 


\section{Figure legends}

646 Figure 1 - Distribution of the 335 sampling sites used in this study (green dots), the watercourses

647 and the three main basins considered in northern Italy.

648

649 Figure 2 - Spatial distribution of exotic abundances in the study area (a) and respective

650 abundances of generalist traits within different ecological functions. Feeding - Generalists (b),

651 Reproduction - Polyphils (c), Tolerance - Low oxygen tolerants (d) and High temperature

652 tolerants (e), Habitat use - Eurytopics (f) and Wide range of turbidity conditions (g).

654 Figure 3 - Plot of distance-based RDA of all species (a), native species (b) and exotic species (c)

655 fish ecofunctional traits composition (colored labels) using geographical variables, land cover

656 classes, water physico-chemical variables as explanatory variables (black labels). Fish

657 ecofunctional traits abbreviations are given in Table 1.

659 Figure 4 - Ecofunctional uniqueness of fish communities along a stream order gradient based on

660 Local Contribution to Beta Diversity, LCBD (a) and contribution of each fish guild to

661 uniqueness based on Species Contribution to Beta Diversity, SCBD (b). Uniqueness patterns

662 were also analyzed separately for native (LCBD (c), SCBD (d)) and exotic (LCBD (e), SCBD

663 (f)) species. Guild abbreviations are given in Table 1.

664 